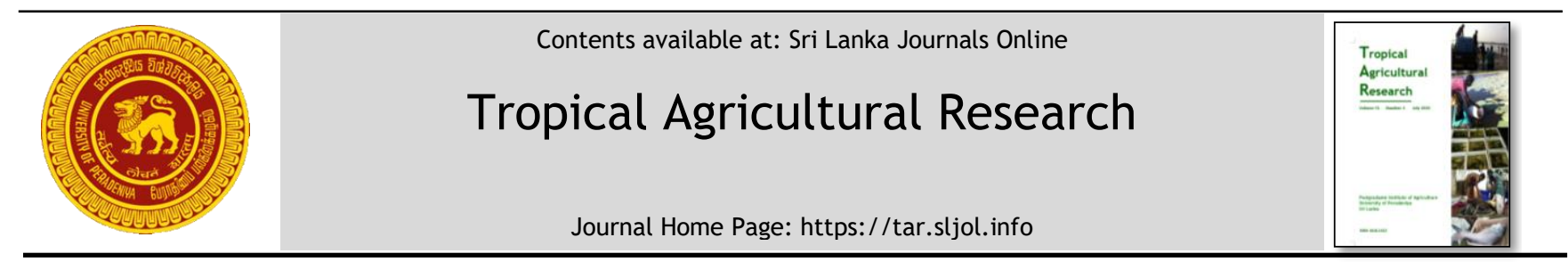

\title{
Effects of Non-Tariff Measures on Seafood Exports from Sri Lanka: A Gravity Approach
}

\author{
K.P.G.L. Sandaruwan ${ }^{1^{*}}$, S.A. Weerasooriya ${ }^{2}$ and J. Weerahewa ${ }^{2}$ \\ ${ }_{1}^{1}$ Postgraduate Institute of Agriculture, University of Peradeniya, Peradeniya, Sri Lanka \\ ${ }^{2}$ Department of Agricultural Economics and Business Management, Faculty of Agriculture, University of Peradeniya, \\ Peradeniya, Sri Lanka
}

\section{ARTICLE INFO}

\section{Article history:}

Received: 14 August 2019

Accepted: 11 November 2019

Revised version received: 22 May 2020

Available online: 1 July 2020

\section{Keywords:}

Gravity model

Non-tariff measures

Seafood

Sri Lanka

Tariff equivalent

\section{Citation:}

Sandaruwan, K.P.G.L., Weerasooriya, S.A. and Weerahewa, J. (2020). Effects of NonTariff Measures on Seafood Exports from Sri Lanka: A Gravity Approach. Tropical Agricultural Research, 31(3): 11-24.

DOI: http://doi.org/10.4038/tar.v31i3.8393

Sandaruwan, K.P.G.L.

https://orcid.org/0000-0002-6393-3591

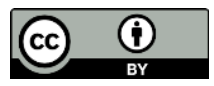

\begin{abstract}
Seafood exports are an attractive market, which has globally grown over time. However, access to the international seafood market is difficult as seafood is highly regulated by Non-Tariff Measures (NTMs). A better understanding of NTMs is needed to conquer the global seafood market. The objective of this study is to investigate the changes in the structure of NTMs imposed by importing countries on Sri Lankan seafood products and to determine the effects of NTMs on seafood exports from Sri Lanka. A gravity model was estimated using a panel dataset consisting of NTMs at 3-digit level, tariffs, gross domestic product, distance, and population for 107 countries covering 144 seafood products between 2001 and 2017. Results revealed that the most critical NTM types of Sri Lankan seafood exports are Sanitary and Phytosanitary Measures (SPS), Technical Barriers to Trade (TBT), and Pre-Shipment Inspections (PSI). Growing trends of NTMs and decreasing trends of tariffs indicate a substitution of NTMs in place of tariffs. Country-wise analysis of NTMs showed that developed countries imposed a higher frequency of NTMs than developing countries. Results of the gravity model suggested that NTMs, tariffs, and distance to the importer have a negative effect, and the GDPs of the importers and Sri Lanka have a positive effect on seafood exports. Tariff equivalent values were calculated based on the elasticities obtained from the gravity model. Results depict that the total NTMs, SPS, TBT, and PSI increase the price of seafood by $62 \%$, $48 \%, 15 \%$, and $13 \%$ respectively. This implies that different NTMs have different impacts on seafood exports from Sri Lanka. Hence, the impact of each NTM type warrants separate attention during policy formulation.
\end{abstract}

*Corresponding author : kariyawasam.lahiru@gmail.com 


\section{INTRODUCTION}

As an island in the Indian Ocean, Sri Lanka is endowed with a large coastal area equal to eight times the size of the country's land extent (Department of Fisheries and Aquatic Resources, 2018). The Indian Ocean is among one of the biodiversity-rich marine ecosystems in the world. Sri Lanka has great potential to develop its fisheries sector and supply the world seafood market with diversified seafood products (Keesing and Irvine, 2005). In 2017, seafood represented $2.2 \%$ of Sri Lankan total merchandise exports (Department of Fisheries and Aquatic Resources, 2018). Sri Lanka was the secondlargest exporter of fresh and chilled swordfish and tuna to the European Union in 2013 (Sandaruwan and Weerasooriya, 2019). The United Nations (2018) highlighted the importance of a blue economy as one of the best approaches to achieve sustainable development goals of Sri Lanka. The budget of Sri Lanka in 2018 named seafood as a bluegreen enterprise and allocated USD 26 million budget to develop the seafood industry. As Sri Lanka expands the export-oriented fisheries industry, it is essential to have a sound basis on which to understand the economic effects of various trade regulations, and plan to reduce unintentional economic costs, if any, of market forces (De Melo and Shepherd, 2018).

United Nations Conference on Trade and Development (UNCTAD) has defined NTMs as any trade policy instrument used to regulate international trade other than ordinary tariffs (UNCTAD, 2015). In the last three decades, the NTMs have been dominant in the world market over tariffs (Niu et al., 2018). Fish is severely regulated under NTMs due to its perishable nature (Fugazza, 2017). The continued growth of frequency and diversity of NTMs may impose higher risks and additional costs to fish exports from Sri Lanka.

Several empirical studies highlight both positive and negative effects of NTMs on international trade (Meloni and Swinnen, 2015; Sandaruwan and Weerasooriya, 2019). As positive impacts, NTMs guarantee certain quality attributes of products and consumers' safety (Peterson et al., 2013). The NTMs help mitigate market failures for consumer goods such as externalities, adverse selection, and moral hazard. Some NTMs are demanded by consumers to solve the quality issues and environmental problems stemming from the production process (Ing and Cadot, 2017; Sandaruwan and Weerasooriya, 2019). However, NTMs can generate negative effects on trade. For example, NTMs discourage investors from developing countries and repels them from international markets. From a consumer perspective, some NTMs increase the prices, which results in the product becoming less affordable and reducing the selection range (De Melo and Nicita, 2018).

The existence of a large number of diverse NTMs makes it very difficult for traders in terms of compliance and difficult for researchers in terms of studying the effects of NTMs. As a remedial measure, UNCTAD has introduced a taxonomy known as "International classification of non-tariff measures". All the NTMs have been categorized into 16 chapters. These chapters are categorized into three groups as technical NTMs, non-technical NTMs, and exportrelated NTMs. According to the literature, among all NTMs, the technical standards are the major obstacles to fish export in global trade (Niu, 2018). Technical measures include Sanitary and Phytosanitary Standards (SPS), Technical Barriers to Trade (TBT), and PreShipment Inspection (PSI).

Many researchers have applied gravity models to detect the effects of NTMs on seafood trade. Debaere (2010) has shown that the restrictiveness of food-safety standards reduced Thai shrimp exports to Europe. Tran and Wilson (2014) found similar results in global crustacean exports. Anders and Caswell (2009) showed contradictory results, which found that larger exporters of seafood to the US benefited from the introduction of safety standards. Rindayati and Kristriana (2018) estimated positive coefficients of NTMs for Indonesian tuna exports. In a different strand of literature, researchers have conducted an in-depth analysis of NTMs in trying to understand the effects of different NTMs separately. Renjini (2016) concluded that the relative rejection rate of Indian fish exports is high because of noncompliance with SPSs, TBTs, and PSI set by the importers. Shepotylo (2015) has pointed out the diverse effects of 
different NTMs. The SPS measures largely influence the variable trade costs, increasing extensive margins of exports, and TBT mostly increases fixed trade costs, reducing extensive margins of export, and increasing intensive margins. In a Sri Lankan context, very few studies have attempted to investigate the impact of NTMs on seafood exports. A more recent study by Sandaruwan and Weerasooriya (2019) used composite indexing techniques to study the impact of NTMs through the European Union's import ban on Sri Lankan seafood and the subsequent impact on Sustainable Development Goals.

Within this milieu, the overall objective of this study was to analyse the effects of NTMs on the seafood export of Sri Lanka. Specific objectives were (i) to investigate the changes in the structure of NTMs on Sri Lankan seafood products during 2001 - 2017, (ii) to study the frequency and diversity of NTMs among different countries, (iii) to identify key determinants which can influence seafood exports of Sri Lanka and (iv) to assess the effects of different NTMs on seafood exports through estimating a tariff equivalent for major NTMs separately.

According to our best knowledge, this was the first time a gravity model approach was applied to understand the effect of NTMs on Sri Lankan seafood exports. We have used panel data to study the seafood trade of Sri Lanka from 2001 to 2017. In international research, it is rather difficult to find studies that deeply probe into NTMs at 3-digit depth. In this study, we explored NTMs at 3-digit depth for 82 countries. The study further aimed at measuring the influence of technical standards, and non-technical NTMs separately on Sri Lanka's fish exports.

\section{MATERIALS AND METHODS}

The methodology was designed to quantitatively explore the effects of NTMs on seafood exports of Sri Lanka by directly comparing NTMs to tariffs. For that, tariff equivalents of NTMs were calculated through first estimating the elasticity of NTMs by implementing a gravity-based model on secondary data collected from international databases.

Gravity model was first proposed by the Nobel laureate Jan Tinbergen in 1962 to explain international bilateral trade. It was named the "gravity model" for its analogy with Newton's law of universal gravitation. Drawing from Newtonian theory, the gravity model proposes that the bilateral trade can be explained by the size of the economies and the distance/proximity. Over the last decade, the usage of gravity models has received recognition as a workhorse model for understanding the 'part-worth' of NTM measures on trade restrictiveness (Xiong and Beghin, 2011). The appropriate variables, modelling errors, and estimation errors have been well identified over time. The main advantage of the gravity approach relies on trade data, which is more abundant at the disaggregated product level than price data. In addition, it can be used for broad panel analysis, i.e. for a large set of countries and products, with different NTMs evolving over time (Niu, 2018). The conventional gravity models continuously suffered because they were unable to address trade cost properly (Kee et al., 2009). Anderson and Van Wincoop (2003) incorporated multilateral trade resistance variables into a structural gravity equation as proxies for the trade cost. The multilateral trade resistance includes anything that causes a change in the average trade cost between a country and its trading partners. More recently, researchers have used a variety of proxies for the multilateral trade resistance such as distance to exporting destination, trade prices, consumptionpreferences, preferential trade agreements, tariff, and non-tariffs (Dou et al., 2015). This study employs distance between Sri Lanka and importing country, tariffs and NTMs to represent trade cost. More advanced gravity studies extend the estimation process to the calculation of tariff equivalent rates or advalorem tariffs. It allows comparing the effects of NTMs with the effects of an equivalent tariff. The basic idea is that once the price and quantity effects are known, it is possible to identify a tariff that would have the equivalent effect (Kee et al., 2009). 
This methodology consisted of four steps. First, the data collected from secondary sources were organized and cleaned as a panel database. Second, testing was done to check for validity of the assumptions of panel data regressions. Third, different regressions were estimated for the database and the findings were compared to select the most appropriate model. Fourth, the elasticities obtained from the third step for the NTMs were used to calculate tariff equivalent.

In order to examine the determinants of seafood exports of Sri Lanka, a panel data econometric procedure was used to enable two-way estimation of both time and space, to address the heterogeneity issues and to avoid bias miss-specified estimation (Goméz and Milgram, 2009). The database included data from 2001 to 2017, from 107 countries regarding 144 products in the Harmonised System (HS) 6-digit level. Altogether, 31,603 observations were included in the database. Data for this study originated from several sources. The fish export data were extracted from the United Nations Commodity Trade Statistics Database (COMTRADE) and through the trade-map. GDP, population, and the bilateral distance between the capital cities of Sri Lanka and the importing countries were taken from the Institute for Research on the International Economy (CEPII). The data on NTMs were obtained from the Trade Analysis Information System (TRAINS) of the UNCTAD. The tariff rates at the HS 6-digit level were obtained from TRAINS and the WTO Integrated Data Base provided by World Integrated Trade Solutions (WITS).

The Ordinary Least Squares (OLS) necessitates dropping observations in which the dependent variable is equal to zero in levels since $\log (0)$ is undefined. Some researchers assign a small value for zero, which could potentially distort the data, but that approach has been criticized in the literature. As a remedial measure, recent studies have employed Poisson PseudoMaximum Likelihood (PPML) techniques for estimating a gravity model (Niu, 2018; Arvis and Shepherd, 2012). PPML can counter the heteroscedasticity problems in the log-linear form of gravity variables due to the existence of many zero values. Silva and Tenreyro (2006) tested this estimator against other methods and found its performance satisfactory even in the presence of measurement errors. The multicollinearity among variables was analysed using the Variance Inflation Factor (VIF) estimation. Even though the frequencies of NTMs were collected for this research, Vigani et al. (2012) have highlighted that there is a possibility of endogeneity between NTM frequency and export value because there is a higher possibility to set more NTMs on the products that are greatly consumed and frequently imported by importers. As suggested by the WTO and The United Nations (2012), the dummy variable ( 1 if NTMs presents 0 if NTMs not presents) of NTMs was selected as an alternative variable due to a couple of reasons. First, the dummy of NTMS displayed a high correlation with NTM frequency. Second, it is unlikely that the dummy of NTMs would correlate with the export values (i.e. whether or not NTMs were present wasn't influenced by the export values). Data analysis was carried out through Microsoft Excel and STATA software packages. The empirical gravity model is given below.

$$
\begin{aligned}
& \ln X_{i j t}^{k}=\beta_{1} \ln G D P_{i t}+\beta_{2} \ln G D P_{j t}+ \\
& \beta_{3} \ln D I S_{i j}+\beta_{4} \ln \left(1+T_{i j t}^{k}\right)+\beta_{5} D N T M_{i j t}^{k}+ \\
& \varepsilon_{i j t}^{k}
\end{aligned}
$$

where $X_{i j t}^{k}$ is the export value of product $k$ to the $i^{\text {th }}$ importing country from Sri Lanka at time $t, G D P_{i t}$ is the gross domestic product of $i^{\text {th }}$ import country at time $t, G D P_{j t}$ is the gross domestic product of Sri Lanka at time $t, D I S_{i j}$ is the distance between the capital of the $i^{\text {th }}$ import country and capital of Sri Lanka, $T_{i j t}^{k}$ is the tariff rate imposed by country $i$ for exported product $k$ from Sri Lanka, DNTM $M_{i j t}^{k}$ is the dummy for total NTMs which equals one if country $i$ has imposed any type of NTM on the exported product $k$ from Sri Lanka and zero otherwise, and $\varepsilon_{i j t}^{k}$ is the error term. A postanalysis was done to estimate the tariff equivalent of the NTMs coefficients based on the method proposed by Kalaba and Kirsten (2012) given below. 
$\ln \hat{X}_{i j t}^{k}=\beta_{A} \Psi_{i j t}+\beta_{4} \ln \left(1+T_{i j t}^{k}\right)+$ $\beta_{5}(D N T M)_{i j t}$

where $\Psi$ represents all other explanatory variables except tariff rates and NTMs. Predicted difference between a country pair with a tariff and the same country pair without the tariff would be, $\left(\hat{X}^{a}\right.$ - export value with tariff, $\hat{X}^{b}$ - export value without tariff)

$\ln \hat{X}_{i j t}^{a}-\ln \hat{X}_{i j t}^{b}=\hat{\beta}_{4} \ln \left(1+T_{i j t}^{k}\right)-\hat{\beta}_{4} \ln (1)$

Predicted difference between a country pair with NTMs and the same country pair without the NTMs would be, $\left(\hat{X}^{c}\right.$ - export value with NTM, $\hat{X}^{d}$ - export value without NTM)

$\ln \hat{X}_{i j t}^{c}-\ln \hat{X}_{i j t}^{d}=\hat{\beta}_{5}(1)-\hat{\beta}_{5}(0)$

A tariff equivalent of NTMs is the tariff that has the same effect on trade flows. This implies that the left-hand sides of (3) and (4) are equal. As a result, the right-hand sides of (3) and (4) also should be equal. This is given in (5). By solving for $\mathrm{T}$, we get (6) which gives the tariff equivalent of the corresponding NTM.

$\hat{\beta}_{4} \ln \left(1+T_{i j t}^{k}\right)=\hat{\beta}_{5}$

Tariff equivelant $=\exp \left(\frac{\widehat{\beta}_{5}}{\widehat{\beta}_{4}}\right)-1$

\section{RESULTS AND DISCUSSION}

\section{Overview of the variables}

Time invariant mean values were calculated for the independent and dependent variables to summarise the data (Table 1). All the variables have shown an increasing trend with time except distance. The export value, importer, and exporter GDP and distance data were available for all 107 countries. The export values were measured in nominal prices because deflating exports using price indices would not adequately capture the unobserved multilateral resistance terms, and could produce misleading results (Shepherd, 2012). GDP data were in constant terms in 1990 as the base year. NTMs and tariff data were available for 82 and 91 countries respectively. A comprehensive study done by the Food and Agriculture Organisation (2006) based on tariff data for 169 countries regarding global seafood, found that seafood was highly regulated compared to other agricultural products. According to the report, the tariff rates varied between 0 and $55 \%$ with a mean value of $15 \%$. Results obtained from our study are in line with their findings. If a closer look was taken at NTMs imposed against Sri Lankan fish exports, there were 3,984 NTMs enforced by importing countries. Because of the perishable nature and potential for food poisoning incidences, fisheries products were highly regulated with food safety-related NTMs compared to other agriculture products (Fugazza, 2017).

All types of NTMs of every export destination have increased continuously. Most of the NTMs belonged to chapter A (SPSs) at 57\% of the total NTMs. The second highest NTMs type was chapter B (TBTs) at $22 \%$. When NTMs were studied at the 3-digit level, labelling, certification, inspection, residual limitations, authorization, and testing were prominent. We further found that fish products that belong to a fresh form of crustacean and mollusc families such as crabs, lobsters, shrimps, and cuttlefish were highly regulated. Fish products coming from phylum Echinodermata and Cnidaria such as sea cucumber, sea urchins, and jellyfish were the least regulated by NTMs.

Figure 1 shows changes in export value with time. Three steep drops could be seen in 2005 (after tsunami disaster), 2010 (removal of the GSP+ tariff concession), and 2015 (European Union fish import ban). The rapid growth of the fish export sector of Sri Lanka can be seen after 2016 because the European Union removed the import ban and Sri Lanka regained GSP+. Even though Sri Lanka has exported 144 seafood products (at HS6 level) during the last 17 years, $72 \%$ of them were sold at less than 5 tons per year. The frozen yellowfin tuna and other tuna species, frozen shrimps, and prawns were the highly exported seafood products. 
Table 1. Descriptive statistics of the variables used in the estimation

\begin{tabular}{lccccc}
\hline Variables & Units & Mean & Std. Error & Minimum & Maximum \\
\hline Export value & USD Million & 0.08 & 0.004 & 0 & 32.42 \\
Importers' GDP & USD Billion & 1,777 & 18.32 & 0.03 & 17,305 \\
Exporters' GDP & USD Billion & 55.83 & 0.09 & 33.74 & 82.39 \\
Distance & Km in 1,000 & 6.75 & 0.02 & 0.77 & 17.44 \\
Tariff & Percentage & 14.47 & 0.05 & 0 & 53 \\
Total NTMs & Number & 21.19 & 0.12 & 0 & 153 \\
SPSs & Number & 12.81 & 0.068 & 0 & 66 \\
TBTs & Number & 6.33 & 0.047 & 0 & 83 \\
Pre inspections & Number & 0.54 & 0.005 & 0 & 6 \\
Non-technical NTMs & Number & 1.51 & 0.014 & 0 & 15 \\
\hline
\end{tabular}

Source: Author's calculation based on the panel dataset

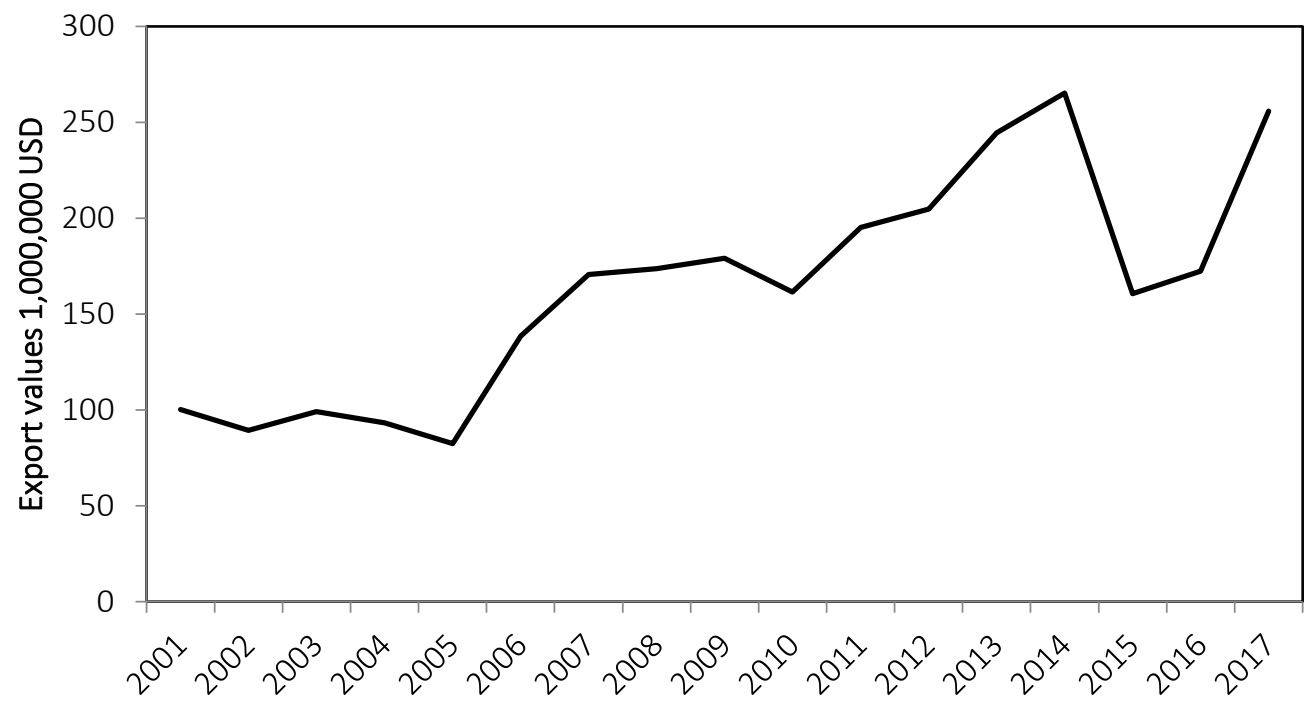

Figure 1. Value of fish exports from Sri Lanka between 2001 and 2017

Source: Prepared by the authors based on the COMTRADE database

According to Figure 2, the tariff rate has slightly declined and NTMs have rapidly increased. Pearson correlation results proved that there is a negative and moderate correlation existing between tariff rates and the number of non-tariff measures (correlation $=-0.438, p=0$ ). Similar findings have been obtained by previous studies and they have concluded that NTMs act as substitutes for tariffs rather than complements (Kareem, 2014). Niu (2018) found that the substitution between tariff and NTMs were very high in the agriculture sector compared to other sectors. Wei et al. (2016) found the global average tariff rates (simple average rates) on agricultural products (HS codes 01-24) have declined from $14.6 \%$ to $10.8 \%$ from 1996 to 2015 . 
The report of the WTO committee overview of the SPS agreement reported 2,553 regular and emergency measures from 1995 to 2002, 5,737 in the next eight years from 2003 to 2010, and 7,848 in the last eight years from 2011 to 2018 (World Trade Organisation, 2019). Not only have the numbers of NTMs but also types of NTMS increased with time. According to the extracted data from the UNCTAD TRAINS database, there were 51 types of NTMs (at the 3-digit level of NTMs classification under UNCTAD) in 2001 and it has increased up to 77 types in 2017. This implies that the variety of NTMs also increased with time. Hoekman and Nicita (2018) explained that there is an increase in compliance cost when there is an increase in the variety of NTMs due to the complicatedness of export rules and regulations.

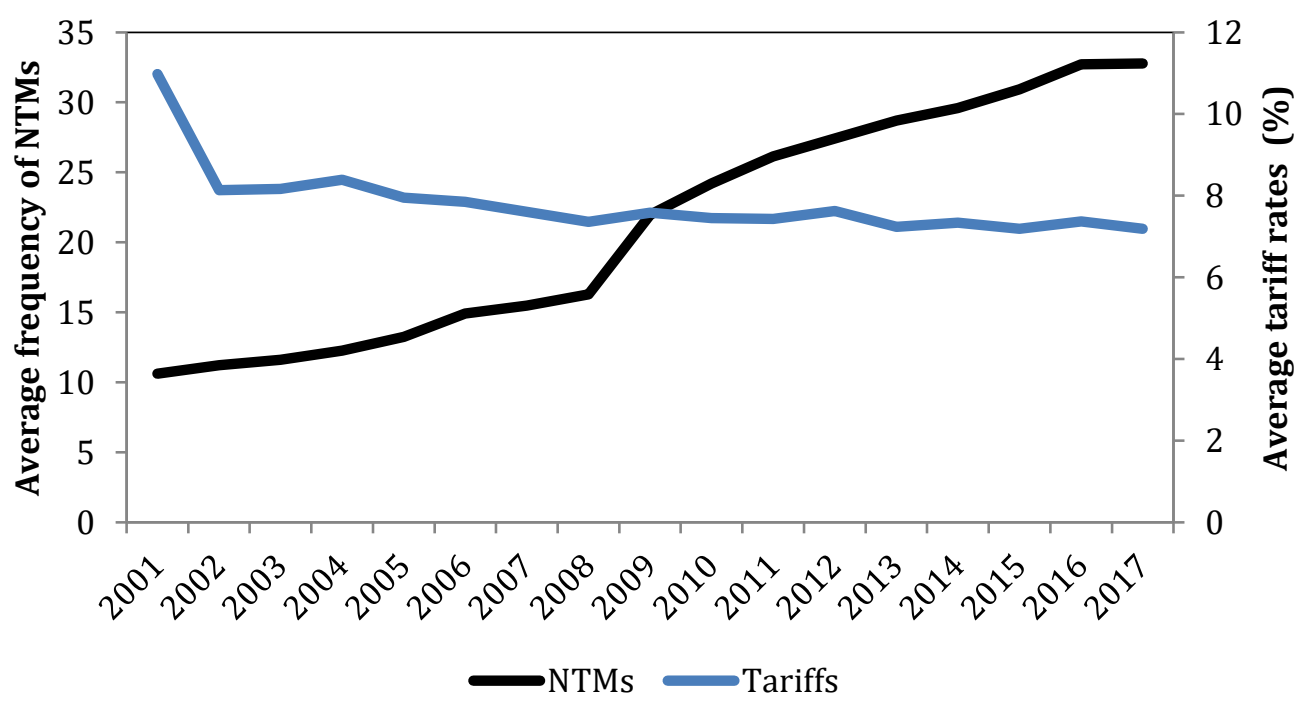

Figure 2. NTM frequency and average tariff rates from 2001-2017

Source: Prepared by the authors based on the COMTRADE database

\section{The development status of the importer and NTM frequency}

All the countries included in the sample were categorized as developed and developing countries based on the categorization in "World economic situation and prospect 2019" by the United Nations. The seafood market of developed countries is very important for Sri Lanka because Sri Lanka exports $85 \%$ of its seafood to developed countries. The difference in the wholesale market price of seafood between developed and developing countries are an attractive factor for exporters. On average, the wholesale price difference of seafood between developed and developing countries were found to be USD 11 . In addition, developed countries frequently import high-value fish species from developing countries. According to the research findings, $71 \%$ of the export basket of developing countries consisted of expensive fish species such as lobsters, prawns, and yellow-fin tuna. Welch's t-test was performed with the development status of the country and the number of NTMs imposed by each country. Developed countries have imposed significantly higher number of NTMs than developing countries $(\mathrm{t}=4.935, \mathrm{df}=79, \mathrm{p}=0.01)$. This implies that it is difficult to export to developed countries because they require a comparatively high number of product standards. 


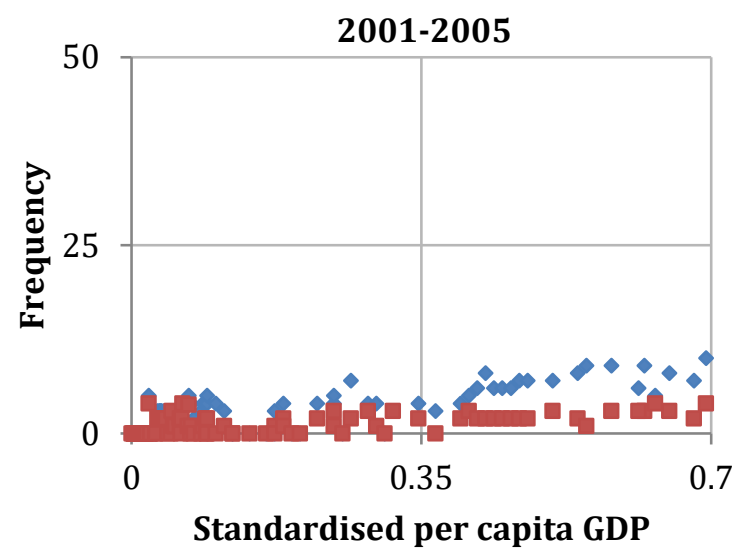

- SPSs $\square$ TBTs

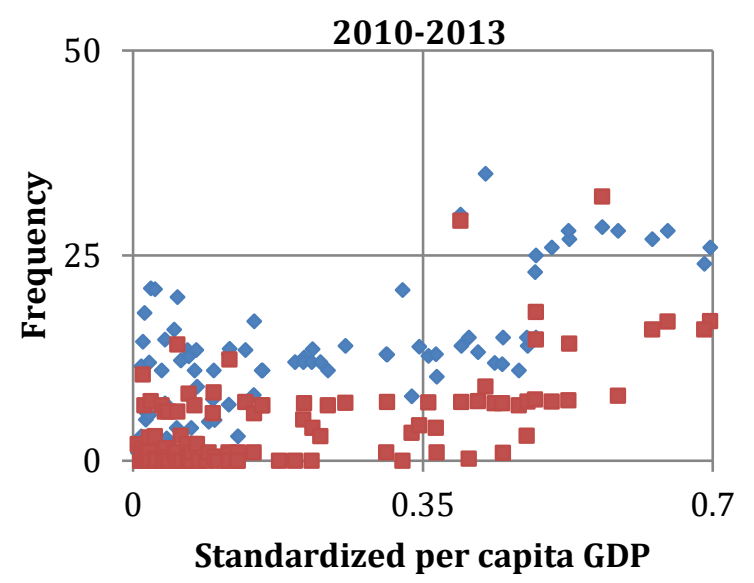

- SPSs $\quad$ TBTs

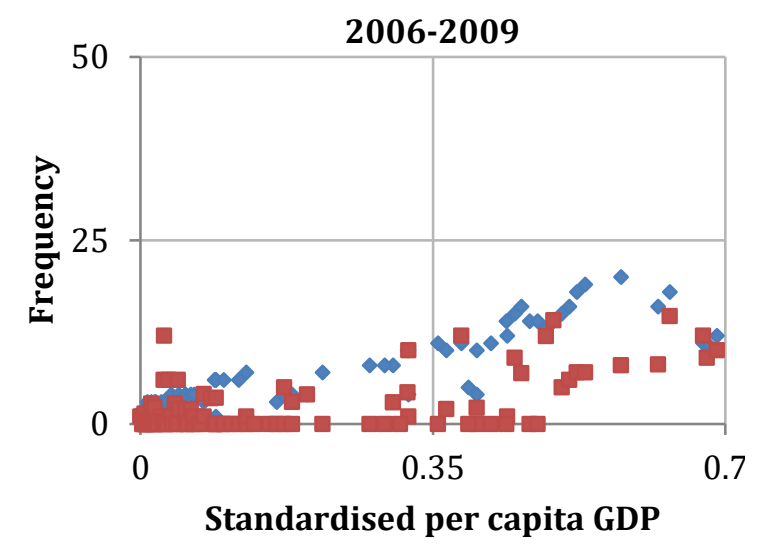

- SPSs $\square$ TBTs

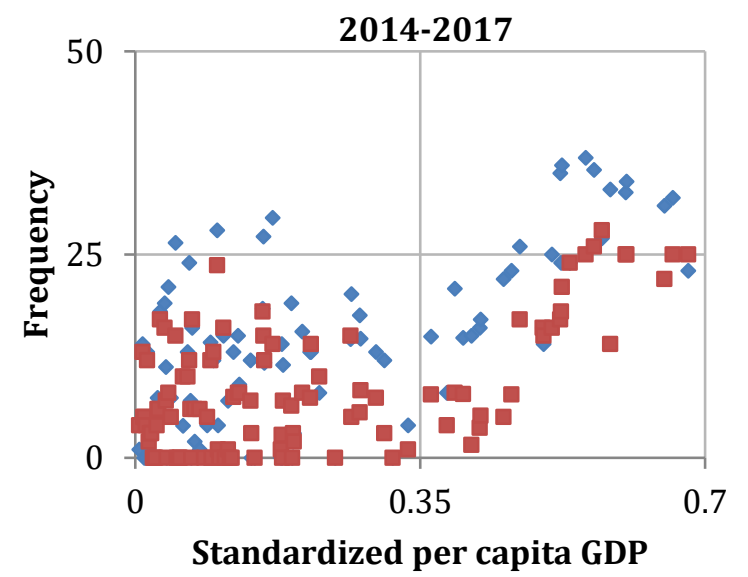

- SPSs - TBTs

Figure 3. Relationship between NTM frequency and GDP per capita Source: Prepared by the authors based on the COMTRADE database

Disdier et al. (2008) found mixed effects on the impact of NTMs. They found that NTMs significantly reduce the exports from developing countries, but it does not affect the bilateral trade between developed countries. As the developing country is dropped from the market due to difficulties in adopting new NTMs, developed countries grab the opportunities by quickly adjusting their value chain to address the NTM requirements. NTMs are highly applied in countries like China, Australia, the USA, New Zealand, and European Union countries. Figure 3 depicts the relationship between NTM frequencies and GDP per capita. In the early half of the previous decade (from
2001-2005), NTMs were not popular. The majority of countries with lower GDP per capita did not enforce NTMs to control the trade. The country with a higher GDP per capita enforced SPSs to ensure consumer safety. With time, many countries have increased both diversity and frequency of NTMs. Especially, TBTs have become prominent as much as SPSs. The increase of diversity and frequency of NTMs is a great challenge for the exporters because they have to now change and adapt their production process to address these unique requirements of different NTMs of each country which ultimately would increase the compliance cost. 


\section{Determinants of Sri Lankan fish exports}

The Levin, Lin, and Chu test results of all the variables have shown probability values less than 0.05 . The results revealed that all the natural log-transformed independent variables are stationary at the level and suitable for panel data analysis. The dataset had $82 \%$ of zero values observed in the dependent variable. Hence, the OLS estimation had a significant heteroscedasticity problem. The variables population, production, and frequency of NTMs reported VIF values greater than 10 implying multi-collinearity. As a result, these variables were removed from the model. To represent the frequency of NTM, a dummy variable for NTMs was introduced. Dummy variables for SPSs and TBTs were correlated with the dummy variable for total NTMs. To solve this multicollinearity issues among different NTMs, separate models were estimated for each NTM type.

This study followed the assumptions of Poisson family regressions. The Poisson family estimator does not require assumptions of normality. The issue of heteroscedasticity was assumed to be countered by the selection of the Poisson regression. In addition, the Poisson family regression coefficients can be used as elasticity values without transformation and it takes care of the presence of zero trade flows, making it a very attractive choice for empirical gravity analysis (Yotov et al., 2016; Shepherd, 2012). There are several Poisson family regression techniques which are employed in the literature. We used these Poisson family regressions and negative binomial regression (NBR) to select the best model and to check the robustness of the selected model. The panel Poisson randomeffects (RE) and fixed-effects (FE), zeroinflated Poisson regression (ZIP), and PPML model were estimated under the Poisson family. Negative binomial regression was used as it counters the restrictive assumption of equal mean and variance in Poisson regression.
Table 2 reports the Poisson RE, FE, PPML, ZIP, and NBR estimators. The zero value of Chi-square proves that all the estimators were statistically significant and most variables of each estimator were significant at a 5\% level. The effects of the independent variables on the export value of bilateral trade were of the same sign and significant at less than $10 \%$ across all 5 regression models. However, most magnitudes of the coefficients differ substantially between the models. The coefficient for distance in the FE model was positive and large due to the lack of temporal variation in the distance variable (i.e. the distance between the two countries will not change over time). The performance of Poisson RE, FE, PPML, ZIP, and NBR were inspected by using the Akaike Information Criterion (AIC) and Bayesian Information Criterion (BIC). PPML estimator resulted in the lowest AIC and BIC values, implying that the PPML should be preferred over the other four estimators.

According to the results of the PPML estimation, the factors that significantly affect the export of Sri Lankan seafood export were found to be the GDP of the importing country, GDP of Sri Lanka, distance to the importing country, the tariff rate of importing countries, and NTMs in importing countries. The relatively large coefficient of tariff (-2.871) indicated a large effect on the export value of Sri Lankan seafood. An increase of $1 \%$ of the tariff in export destination countries was estimated to decrease $2.87 \%$ of the value of Sri Lankan seafood to export destination countries, ceteris paribus. The critical concern about this research was the effect of NTMs. Compared to no NTMs, when there are NTMs imposed, the seafood exports decrease by $37.6 \%$ ceteris paribus $\left(e^{-0.472}-1=\right.$ -0.376 ). This implies that NTMs reduces Sri Lankan seafood exports. In addition, the GDP of both the importing country and Sri Lanka enhance seafood exports significantly, while the distance between the capitals of the importing country and Sri Lanka decrease the export values. 
Table 2. Results of the gravity model estimations

\begin{tabular}{lccccc}
\hline \multicolumn{1}{c}{ Variables } & Poisson (RE) & Poisson (FE) & PPML & ZIP & NBR \\
\hline \multirow{2}{*}{ In_Importer GDP } & $1.896^{* * *}$ & $2.025^{* * *}$ & $0.599^{* * *}$ & $0.401^{* * *}$ & $0.723^{* * *}$ \\
& $(0.041)$ & $(0.011)$ & $(0.035)$ & $(0.000)$ & $(0.067)$ \\
In_Exporter GDP & $1.178^{* * *}$ & $1.134^{* * *}$ & $1.02^{* * *}$ & $0.715^{* * *}$ & $1.628^{* *}$ \\
& $(0.005)$ & $(0.005)$ & $(0.077)$ & $(0.002)$ & $(0.132)$ \\
In_Distance & $-1.915^{* * *}$ & 31.797 & $-0.364^{* *}$ & $0.144^{* * *}$ & $-1.102^{* *}$ \\
& $(0.059)$ & $(1,042)$ & $(0.067)$ & $(0.002)$ & $(0.070)$ \\
In_(1+Tariff) & $-1.586^{* * *}$ & $-1.490 * * *$ & $-2.871^{* *}$ & $-1.426^{* * *}$ & $-0.907^{*}$ \\
& $(0.038)$ & $(0.038)$ & $(0.334)$ & $(0.011)$ & $(0.568)$ \\
Dummy NTM & $-1.110^{* * *}$ & $-1.108^{* *}$ & $-0.472^{* *}$ & $-0.328^{* * *}$ & $-0.355^{* * *}$ \\
& $(0.002)$ & $(0.002)$ & $(0.019)$ & $(0.000)$ & $(0.111)$ \\
Constant & $-1.167^{* * *}$ & $2.288^{* * *}$ & $1.160^{* * *}$ & $2.100^{* * *}$ & $0.736^{* * *}$ \\
& $(0.116)$ & $(0.253)$ & $(0.147)$ & $(0.006)$ & $(0.230)$ \\
N & 26,093 & 26,093 & 26,093 & 26,093 & 26,093 \\
chi2 (test) & 7,028 & 9,512 & 7,480 & $1,430,000$ & 9,252 \\
Prob. Chi-square & 0 & 0 & 0 & 0 & 0 \\
AIC & $2,226,036$ & 582,716 & 216,134 & $8,526,569$ & 902,057 \\
BIC & $2,226,102$ & 582,765 & 216,200 & $8,526,642$ & 902,629 \\
\hline
\end{tabular}

Robust standard errors are in parentheses.

${ }^{*},{ }^{* *}$ and ${ }^{* * *}$ asterisks denote significance at $10 \%, 5 \%$ and $1 \%$ levels, respectively.

Source: Prepared by the authors based on the regression estimates

\section{Tariff equivalent of NTMs}

The PPML model was estimated with a dummy variable in place for total NTMs (i.e. 1 if any type of NTM is imposed and 0 otherwise). The PPML model was reestimated with an alternative specification for the dummy variable for SPSs, TBTs, preinspections, and non-technical NTMs (i.e. 1 if the specific type of NTM is imposed and 0 otherwise). The coefficient values of tariff and relevant NTMs types were plugged into the equation (6) and the equivalent tariff values were calculated which are given in table 3. In a Sri Lankan context, total NTMs had a $62.38 \%$ tariff equivalent of NTMs on Sri Lankan seafood. Among the NTM types, SPS was the major type of NTM which had a $48.66 \%$ tariff equivalent of NTMs on Sri Lankan seafood. In addition, other NTM types such as TBT, pre-inspections and nontechnical NTMs resulted in tariff equivalents of $15.4 \%, 13.36 \%$ and $30.94 \%$ respectively. In literature, we found no previously calculated tariff equivalent of NTMs in a Sri Lankan context. Hence the results of this study were compared with international studies. The findings of this study tally with most of the previous research findings. Grübler (2016) has estimated tariff equivalent for meat and fishery products of the world at 35\%. Kalaba and Kirsten (2012) used a similar approach to estimate the tariff equivalent for NTMs of milk and meat products. They found that the equivalent values can range from $10 \%$ to $400 \%$. Adriamananjara et al. (2004) estimated the ad-valorem equivalent of NTMs for 12 products in 18 regions/countries using the GTAP model. 
The range of estimates for apparels was between $16 \%$ and $190 \%$. Kee et al. (2009) in their estimations of trade-restrictive indicators arrived at an estimate for apparels ranging between $0 \%$ and $249 \%$.

Table 3. Tariff equivalent values of different NTMs types of Sri Lanka

\begin{tabular}{lccc}
\multicolumn{1}{c}{ NTM types } & $\begin{array}{c}\text { NTM } \\
\text { coefficient }\end{array}$ & $\begin{array}{c}\text { Tariff } \\
\text { coefficient }\end{array}$ & Tariff equivalent (\%) \\
\hline Total NTMs & -0.472 & -2.87 & $\mathbf{6 2 . 2 8}$ \\
SPS & -0.326 & -1.99 & $\mathbf{4 8 . 6 6}$ \\
TBT & -0.119 & -1.67 & $\mathbf{1 5 . 4 0}$ \\
PSI & -0.359 & -2.52 & $\mathbf{1 3 . 3 6}$ \\
Non-technical NTMs & -0.256 & -2.52 & $\mathbf{3 0 . 9 4}$ \\
\hline
\end{tabular}

Source: Prepared by the authors based on the regression estimates

\section{CONCLUSION}

This paper attempted to provide some of the first empirical evidences on the effect of NTMs imposed by importers on Sri Lankan seafood export. The growing trends of NTMs and the decreasing trends of tariffs prove that the importers substitute NTMs for tariffs to control trade. This research found a positive relationship between GDP per capita and the frequency of NTMs. The results indicated that seafood entering the market of a developed country needs to comply with a substantial number of NTMs than developing countries. It is a critical concern for a seafood exporter like Sri Lanka because $85 \%$ of Sri Lankan seafood exports target developed countries. Sri Lanka can earn higher income from the market of developed countries because customers in developed countries purchase high valued fish species under higher prices. The frequency of NTMs and the diversity of NTMs have increased with time. When the diversity of NTMs is increased, the production cost rapidly increases because producers have to customize the production process in different ways to comply with the number of unique NTMs (Hoekman and Nicita, 2018). As a special feature of this research paper, different NTMs types (TBTs,
SPSs, pre-inspection, and non-technical NTMs) have been evaluated separately. The findings suggested that all the NTM types continuously increase in all import destinations. The changing NTMs of seafood in the world had statistically significant and negative effects on the Sri Lankan trade flow of seafood, over the study period 2001-2017. The literature suggested that the importing countries should understand the optimal level of NTMs that can reduce the negative effects of NTMs on trade (Xiong and Beghin, 2011). In addition, the relevant institutes of the exporting country should support the producers and exporters to quickly adopt changing NTM requirements by providing easy access for quality and health certification, completing the supporting facilities for pre-processing and postprocessing with additional incentives. The unavailability of NTMs data for some countries (in the UNCTAD database) was a major issue for this research. It is recommended to conduct country-level literature surveys to find the information on such NTMs. The regional trade agreements and exchange rate variation are also critical determinants for bilateral trade. There is a possibility to include such variables into the model and improve the model for future research. 


\section{REFERENCES}

Adriamananjara, S., Dean, J.M., Feinberg, R., Ferrantino, M.J., Ludema, R. and Tsigas, M. (2004). The effects of nontariff measures on prices, trade and welfare: CGE implementation of policy-based price comparisons. International Trade Commission, Working Paper No. 04. A. Washington DC. USA.

Anders, S.M. and Caswell, J.A. (2009). Standards as barriers versus standards as catalysts: Assessing the impact of the HACCP implementation on U.S. seafood imports. American Journal of Agricultural Economics. 91(2), 310-321.

Anderson, J.E. and Van Wincoop, E. (2003). Gravity with gravitas: A solution to the border puzzle. American Economic Review. 93(3), 170-192.

Arvis, J.F. and Shepherd, B. (2013). The Poisson quasi-maximum likelihood estimator: A solution to the 'adding up 'problem in gravity models. Applied Economics Letters. 20(6), 515-519.

Debaere, P. (2010). Small fish-big issues: The effect of trade policy on the global shrimp market. World Trade Review. 9(2), 315-353.

De Melo, J. and Nicita, A. (2018). Non-tariff measures: Data and quantitative tools of analysis. In "Non-tariff measures: Economic assessment and policy options for development." J. De Melo and A. Nicita (eds.), United Nations Conference on Trade and Development. Geneva, Switzerland, pp. 81-120.

De Melo, J. and Shepherd, B. (2018). The economics of non-tariff measures: A primer. In "Non-tariff measures: Economic assessment and policy options for development." J. De Melo and A. Nicita (eds.), United Nations Conference on Trade and
Development. Geneva, Switzerland, pp. 121-158.

Department of Fisheries and Aquatic Resources. (2018). The annual statistics of fisheries sector 2017, Publication of Ministry of Fisheries and Aquatic Resources Development. Colombo, Sri Lanka.

Disdier, A., Fontaigné, L. and Mimouni, M. (2008). The impact of regulations on agricultural trade: Evidence from the SPS and TBT agreements. American Journal of Agricultural Economics. 90(2), 336-350.

Dou, L., Yanagishima, K., Li, X., Li, P. and Nakagawa, M. (2015). Food safety regulation and its implication on Chinese vegetable exports. Food Policy. 57(3), 128-134.

Food and Agriculture Organisation. (2006). Tariff in world seafood trade: FAO fisheries circular 1016, Rome, Italy.

Fugazza, M. (2017). Fish trade and policy: A primer on non-tariff measures. UNCTAD/ESCAP Working Paper No. 7. Geneva, Switzerland.

Goméz, E.H. and Milgram, J.B. (2009). Are estimation techniques neutral to estimate gravity equations? An application to the impact of EMU on third countries' exports. Universidad de Granada.

Grübler, J., Ghodsi, M. and Stehrer, R. (2016). Assessing the Impact of Non-Tariff Measures on Imports Monthly report of The Vienna Institute for International Economic Studies, Austria.

Hoekman, B. and Nicita, A. (2018). Non-tariff measures: Data and quantitative tools of analysis. In "Non-tariff measures: Economic assessment and policy options for development." J. De Melo and A. Nicita (eds.), United Nations Conference on Trade and 
Development. Geneva, Switzerland, pp. 13-80.

Ing, L.Y. and Cadot, O. (2017). Ad-valorem equivalents of non-tariff measures in ASEAN, ERIA Discussion Paper Series, No. 09. OECD. Paris, France.

Kalaba, M. and Kirsten, J. (2012). Estimating the quantity of non-tariff measures SADC meat and milk trade, Working paper No. 206513, University of Pretoria, South Africa.

Kareem, O.I. (2014). The European Union sanitary and phytosanitary measures and Africa's exports. European University Institute Working Paper No. 98, Robert Schuman Centre for Advanced Studies, San Domenico Fiesole, Italy.

Kee, H.L, Nicita, A. and Olarreaga, M. (2009). Estimating trade restrictiveness indices. The Economic Journal. 119(4), 172-199.

Keesing, J. and Irvine, T. (2005). Coastal biodiversity in the Indian Ocean: The known, the unknown and the unknowable. Indian Journal of Marine Sciences. 34(1), 11-26.

Meloni, G. and Swinnen, J. (2015), Chocolate regulations, in "The economics of chocolate." M.P. Squicciarini and J. Swinnen (eds.), pp. 268-303. Oxford, UK: Oxford University Press.

Niu, Z. (2018). The rising importance of nontariff measures in China's trade policy. In "Non-tariff measures: Economic assessment and policy options for development." J. De Melo and A. Nicita (eds.), United Nations Conference on Trade and Development. Geneva, Switzerland, pp. 393-420.

Niu, Z., Liu, C., Gunessee, S. and Milner, C. (2018). Non-tariff and overall protection: Evidence across countries and over time: Review of World Economics, 154(4), 675-703.
Peterson, E., Grant, J., Roberts, D. and Karov, V. (2013). Evaluating the trade restrictiveness of phytosanitary measures on US fresh fruit and vegetable imports. American Journal of Agricultural Economics, 95(4), 842858.

Renjini, V.K.K. (2016). Quantifying the effect of non-tariff measures and food safety standards on India's fish and fishery products' exports. Working paper 375, The Institute for Social and Economic Change, Bangalore, India.

Rindayati, W. and Kristriana, W. (2018). Impact analysis of non-tariff measures (NTM) on Indonesian tuna export to major destination countries. Journal of Management \& Agribusiness, 15 (2), 172-185.

Sandaruwan, K.P.G.L. and Weerasooriya S.A. (2019). Non-tariff measures and sustainable development: The case of the European Union import ban on seafood from Sri Lanka, UNCTAD/ESCAP-ART Networking Paper Series, No. 185, Bangkok, Thailand.

Silva, S.J. and Tenreyro, S. (2006). The log of gravity. The Review of Economics and Statistics. 88(1), 641-658.

Shepherd, B. (2012). The gravity model of international trade: User guide. UNCTAD. Bangkok Thailand.

Shepotylo, O. (2015). Effect of non-tariff measures on extensive and intensive margins of export in seafood trade. Working paper. Norwegian Institute of International Affairs, Norway.

Tran, N.T. and Wilson, N. (2014). The differential effects of food safety regulations on animal products trade: The case of crustacean product trade. Agribusiness. 30(1), 31-45.

The United Nations. (2018). Maps approach supporting SDG implementation in Sri 
Lanka. United Nation office in Sri Lanka Colombo.

UNCTAD. (2015). International classification of non-tariff measures. United Nations Conference on Trade and Development. Geneva, Switzerland.

Vigani, M., Raimondi, V. and Olper, A. (2012). International trade and endogenous standards: The case of GMO regulation. Wold Trade Review. 11 (3), 415-437.

Wei, G., Jikun, H.J. and Yang, J. (2016). The impacts of food safety standards on China's tea exports. China Economic Review. 23(1), 253-264.

World Trade Organisation. (2019). Sanitary and phytosanitary information management system. World Trade
Organization. Accessed at spsims.wto.org

World Trade Organisation and the United Nations. (2012). A practical guide to trade policy analysis. World Trade Organization publication. Geneva, Switzerland.

Xiong, B. and Beghin, J. (2011). Disentangling the demand-enhancing effect and trade- cost effect of technical measures in agricultural trade among OECD countries, Working Paper No. 11019. Iowa State University. Ames, Iowa.

Yotov, Y.V., Piermartini, R., Monteiro J.A. and Larch M. (2016). An Advanced Guide to Trade Policy Analysis: The Structural Gravity Model. World Trade Organization. 